\title{
INTERAÇÃO UNIVERSIDADE-EMPRESA: ANÁLISE DE CASO DE DUAS UNIVERSIDADES BRASILEIRAS
}

\author{
University-company interaction: case analysis of two Brazilian universi- \\ ties
}

Cassiane Chais

E-mail: cassichais@gmail.com

Doutora em Administração pela Universidade de Caxias do Sul, com período sanduíche no Tecnológico de Monterrey no México; Mestre em Administração pela Universidade de Caxias do Sul;

Coordenadora do Parque de Ciência Tecnologia da Universidade de Caxias do Sul.

Endereço para contato: Rua Francisco Getúlio Vargas, 1130, 95070-560, Caxias do Sul, Rio Grande do Sul, Brasil.

https://orcid.org/0000-0002-1922-9273

Paula Patrícia Ganzer Pós-doutora em Administração pela Universidade de Caxias do Sul; Doutora em Administração pela Pontifícia Universidade Católica do Rio Grande do Sul; Professora no Instituto Federal de Educação, Ciência e Tecnologia do Rio Grande do Sul. https://orcid.org/0000-0003-4006-6517

Daniel Hank Miri

E-mail: danielmirid@gmail.com

Doutorando em Administração pela Universidade de Caxias do Sul; Mestre em Administração pela Universidade de Caxias do Sul; Vínculo; Professor na Universidade de Caxias do Sul. https://orcid.org/0000-0002-0765-6868

Juliana Matte

E-mail: ju.cxsl@gmail.com Mestre em Administração pelo Programa de Pós-Graduação em Administração da Universidade de Caxias do Sul; doutoranda em Administração pelo Programa de Pós-Graduação em Administração da Universidade de Caxias do Sul; Professora na Universidade de Caxias do Sul. https://orcid.org/0000-0003-0945-2479

Pelayo Munhoz Olea E-mail: pelayo.olea@gmail.com

Pós-doutor em Gestão Ambiental pela Universidad de Extremadura, Espanha; Doutor em Administração e Direção de Empresas pela Universitat Politècnica de Catalunya, Espanha; Professora na Universidade Federal do Rio Grande (FURG). https://orcid.org/0000-0003-2183-8112

Artigo recebido em 18 de fevereiro de 2020. Aceito em 2 de março de 2021. 


\section{Resumo}

A universidade possui um histórico pautado na contribuição para avanço do conhecimento e da tecnologia no contexto socioeconômico de um país, por meio do ensino, da pesquisa e da extensão. $O$ conhecimento gerado pelas pesquisas realizadas por alunos e pesquisadores pode ocasionar a interação com diferentes atores, entre eles as empresas, acarretando a transferência do conhecimento produzido na universidade para o mercado. Diante disso, este artigo teve como objetivo analisar de que forma ocorre a interação universidade-empresa a partir dos casos da Universidade Estadual de Campinas (Unicamp) e da Universidade do Vale do Rio dos Sinos (Unisinos). O método utilizado possui abordagem qualitativa, de natureza exploratória, e caracteriza-se, em termos de delineamento, como um estudo de caso, possuindo como elementos duas Instituições de Ensino Superior brasileiras. Para coleta de dados, além da pesquisa bibliográfica e documental, adotou-se a entrevista semiestruturada realizada com gestores e pesquisadores das universidades. Na análise dos dados, foi empregada a análise de conteúdo, com o tratamento por meio do software NVivo ${ }^{\circledR}$. Os principais resultados evidenciam que empresas e universidades necessitam compreender que é preciso atuar conjuntamente na pesquisa tecnológica colaborativa para que os recursos financeiros investidos pela iniciativa pública ou privada não somente sejam aceitos como artigos publicados em revistas científicas, mas também se transformem em inovações tecnológicas difundidas ao mercado.

Palavras-chave: Universidade empreendedora. Estudo de caso. Spin-offs acadêmicos.

\section{Abstract}

The university's history is based on contributing to the advancement of knowledge and technology in a country's socio-economic context through teaching, research, and extension. The knowledge generated by the research carried out by students and researchers can cause interaction with different actors, among them the companies, leading to the transfer of knowledge produced at the university to the market. In line with the above, this study aimed to analyze how university-company interaction occurs from the State University of Campinas (Unicamp) and the University of Vale do Rio dos Sinos (Unisinos) cases. The method used is of a qualitative approach and exploratory nature, characterized as a case study, having as elements two Brazilian Higher Education Institutions. Besides bibliographic and documental research, a semi-structured interview with university managers and researchers was adopted for data collection. For the data analysis, the content analysis was used, with the treatment through $N V_{i v o}{ }^{\circledR}$ software. The main results showed that companies and universities need to understand that it is necessary to cooperate in collaborative technological research. This way, the financial resources invested by public or private initiatives are not only accepted as articles published in scientific journals but also become technological innovations disseminated to the market.

Keywords: Entrepreneurial university. Case study. Spin-offs academics.

\section{INTRODUÇÃO}

setor empresarial ou a estrutura produtiva busca contato com a universidade almejando a pesquisa tecnológica e inovadora, pois a universidade ainda é o centro principal de produção do conhecimento, embora não seja mais o único, visto que empresas já 
instalaram em suas estruturas departamentos responsáveis por pesquisa básica e pesquisa avançada (Fava-de-Moraes, 2000).

A interação entre universidade e setor produtivo, principalmente para empresas de Pesquisa e Desenvolvimento (P\&D), fica evidenciada a partir de dados do Pintec, um levantamento realizado pelo Instituto Brasileiro de Geografia e Estatística (IBGE) (2016), que indica que as universidades e os institutos de pesquisa estão entre os principais parceiros para cooperação. Representam essa parceira em $82,2 \%$ dos casos em setores como eletricidade e gás, $24,2 \%$ em fornecedores da indústria e $36 \%$ no setor de serviços.

Cabe ressaltar, ainda, a importância de outro ator para que a pesquisa tecnológica e inovadora buscada pelas empresas seja bem-sucedida: o governo, conforme prevê o modelo da tríplice hélice (Etzkowitz, 2013). A tríplice hélice é um modelo de inovação em que a universidade, a indústria e o governo, como esferas institucionais primárias, interagem para promover o desenvolvimento por meio da inovação e do empreendedorismo (Etzkowitz \& Zhou, 2017).

A troca de conhecimento entre universidade e empresa ainda é incipiente, porém governo e universidades têm iniciado algumas ações para que, mediante um ambiente propício à inovação, isso possa ocorrer (Leih \& Teece, 2016). Verifica-se, nesse cenário, a criação de incubadoras e parques tecnológicos, bem como de fundações nas universidades para que possam gerir contratos e convênios de inovação entre empresas, universidades e escritórios de transferência de tecnologia (McClure, 2016).

Duas instituições que integram essa conjuntura são a Universidade do Vale do Rio dos Sinos (Unisinos) e a Universidade Estadual de Campinas (Unicamp). A Unisinos, localizada no Estado do Rio Grande do Sul, foi escolhida como objeto deste estudo por se caracterizar como comunitária privada e sem fins lucrativos, de acordo com a Lei n. 12.881, de 12 de novembro de 2013. A opção por pesquisar essa universidade ocorreu pelo fato de que a região Sul do Brasil possui 51,6\% das instituições privadas do País e apenas $17,9 \%$ das públicas (Formulário para Informações sobre a Política de Propriedade Intelectual das Instituições Científicas, Tecnológicas e de Inovação do Brasil [Formict], 2012). Além disso, 72,4\% das instituições privadas brasileiras já possuem uma política de inovação implementada, o que certamente facilita a interação com o setor produtivo $e$, consequentemente, aumenta os índices de incentivo e motivação dos pesquisadores ao envolvimento com a pesquisa científica voltada para a inovação (Formict, 2012).

Já a Unicamp, localizada no Estado de São Paulo, foi escolhida para integrar este estudo por ser considerada uma Instituição de Ciência e Tecnologia (ICT), de acordo com a Lei n. 10.973, de 2 de dezembro de 2004, e por ser uma instituição pública, de acordo com a Lei n. 9.394, de 20 de dezembro de 1996. Ademais, em uma busca simples em bancos internacionais de patentes, utilizando o termo "Unicamp", foram encontrados 1.245 resultados 
no Espace Net, um banco europeu, e 1.153 resultados na Wipo - PatentScope, um banco norte-americano. Isso evidencia que a Instituição possui foco em inovação, pois a patente é a primeira etapa, de invenção, para se chegar à inovação (Instituto Nacional de Propriedade Industrial [INPI], 2016; World Intellectual Property Organization [WIPO], 2017; Espacenet, 2017).

Para facilitar a interação com a sociedade, desde 2003 a Unicamp conta com a Inova Unicamp, uma agência de inovação com a finalidade de realizar a gestão da inovação dentro da universidade e também o atendimento às empresas e aos empresários que buscam na Instituição novas pesquisas e tecnologias. A capacidade empreendedora da Unicamp e de seus alunos fica patente na medida em que quase uma centena de empresas na região de Campinas nasceu da própria universidade, as chamadas "filhas da Unicamp", sendo em sua maioria empresas de tecnologia de ponta (Unicamp, 2015).

Além disso, a Unicamp foi a segunda universidade brasileira mais bem ranqueada em 2016 no The Times of Higher Education (THE), criado em 2004. Esse ranking avalia também universidades da América Latina, e a Unicamp conquistou uma nota de 91,1 a partir de indicadores como ensino, pesquisa, citações, interação com a indústria e perspectiva internacional. Nesse mesmo ano, no QS World University Ranking, realizado pelo Quacquarelli Symonds (QS), instituto britânico especializado em educação superior e carreira, a Unicamp conquistou o segundo lugar em 2016 e em 2017/2018. No ranking universitário nacional do Jornal Folha de São Paulo, em 2016 a Unicamp ficou em terceiro lugar, com uma nota de 96,77 . Outro importante ranking em que a Instituição obteve destaque foi no índice de Universidades Empreendedoras, lançado em 2016, em que ficou na segunda posição, com nota 6,91 , apresentando-se como a primeira colocada no critério internacionalização.

Segundo dados do Pintec relacionados aos anos de 2012 a 2014 e publicados em 2016, alguns dos motivos que dificultam a inovação nas empresas são a falta de pessoal especializado em $P \& D$, problemas de cooperação com outras empresas e instituições do sistema nacional de inovação e a falta de regulamentação para a área na empresa. Dados como esses justificam a importância de estudos que objetivem analisar de que forma ocorre a interação universidade-empresa, caso deste estudo, que se volta à investigação dessa interação nas instituições Unicamp e Unisinos.

Para isso, este artigo está estruturado em quatro seções além desta introdutória. $\mathrm{Na}$ segunda expõe-se o referencial teórico, em que são descritos os construtos sobre interação universidade-empresa, universidade empreendedora e inovação. Na terceira seção consta - método de pesquisa utilizado para obtenção e análise dos dados. Na quarta seção é apresentada a análise dos resultados. Por fim, na quinta seção estão a conclusão da pesquisa, as limitações e as sugestões de investigações futuras. 


\section{UNIVERSIDADE EMPREENDEDORA}

Desde sua criação, no século $\mathrm{XI}$, na Europa, as universidades estavam voltadas ao ato de transmitir conhecimento de professor para aluno, com foco na atividade de ensino. No século XVII, ocorreu a primeira revolução acadêmica, quando a atividade de pesquisa foi agregada ao ensino, passando a fazer parte da missão das universidades, o que aconteceu primeiramente em universidades da Alemanha e posteriormente em universidades dos Estados Unidos, da Inglaterra e da França (Lopes, 2012). Essa primeira revolução ainda gera debates e desafios no meio acadêmico relativos a como integrar professores e pesquisadores em suas atividades, e até mesmo na gestão universitária, e, também, a como conduzir ambas as atividades dentro do mesmo ambiente acadêmico (Audy \& Morosini, 2006).

A partir do século XIX, outras mudanças marcantes ocorreram, como a expansão de institutos públicos de pesquisa e a criação de departamentos de P\&D estabelecidos em empresas e organizações, assim como novas formas de telefonia. Isso fez com que o mercado obtivesse demanda para cientistas e engenheiros, levando à massificação das universidades (Lopes, 2012).

Esse cenário propiciou uma segunda revolução, que teve início na metade do século XX e que incorporou à missão da universidade, além do ensino e da pesquisa, o desenvolvimento econômico e social, fazendo com que a universidade incluísse em suas funções o papel de agente de inovação e empreendedorismo (Audy \& Morosini, 2006). Essa nova missão, de uma universidade empreendedora e ativa, surgiu a partir de experiências em instituições como Massachusetts Institute of Technology (MIT), Stanford e Harvard, aproximando a academia da sociedade e posicionando-a como um importante agente de transformação econômica e social (Lopes, 2012).

Uma universidade empreendedora envolve a extensão das ideias à atividade prática, capitalizando o conhecimento, organizando novas entidades e gerenciando riscos (Etzkowitz, 2013). Ademais, busca proporcionar um ambiente favorável, no qual a comunidade universitária possa explorar, avaliar e criar ideias passíveis de serem transformadas em iniciativas empreendedoras sociais e econômicas (Guerrero et al., 2016).

O marco das relações universidade-indústria para a inovação foi a Lei Bayh-Dole (Lei Pública 96-517), aprovada nos Estados Unidos em dezembro de 1980, em meio a preocupações com a perda de competitividade do país, e considerada um divisor de águas no que concerne às tecnologias de licenciamento desenvolvidas nas universidades (Stal \& Fujino, 2016). Embora tenha sua origem nos Estados Unidos, a cooperação é mais necessária em países emergentes, onde as universidades constituem a principal fonte de conhecimento que pode levar à inovação, figurando como agentes de mudanças econômicas e sociais (Comissão Econômica para a América Latina [Cepal], 2018). 
Para o desenvolvimento de uma universidade empreendedora, ou seja, de uma universidade que possua entre suas atividades a interação com as empresas e o governo, são imperativas, segundo Etzkowitz (2013), três fases:

a) a universidade precisa estabelecer sua visão estratégica, redefinindo prioridades principalmente financeiras, para prover recursos necessários para suas pesquisas;

b) a instituição deve possuir como foco a comercialização da propriedade intelectual e a transferência de tecnologias;

c) como resultado da soma das duas primeiras fases, a universidade passa a ter um caráter regionalizado, comprometendo-se com a geração de novos empreendimentos, novos produtos e novos processos.

A partir da terceira fase, a universidade começa a construir relações com outros atores, como governo e empresas, desenhando um novo papel no desempenho da inovação para a região em que está inserida, formando, assim, a tríplice hélice. Esse papel não é somente de comercialização do conhecimento, mas também de um desenvolvimento preocupado em produzir impactos sociais e sustentáveis na região (Ełzkowitz, 2013).

O processo de interação ou parceria entre universidades e empresas pode ser de cinco tipos:

a) colaboração, que possui um baixo nível de risco, serviços e inovação e contratos de pesquisa, mas possui um alto grau de pesquisa aplicada e criação de startups;

b) colaboração estratégica bilateral, que possui baixo risco e baixo nível de inovação, assim como forte presença de financiamentos públicos e grandes possibilidades de transferência de tecnologia, requerendo que os parceiros realizem um trabalho em conjunto;

c) pesquisa básica, que possui como objetivo principal a cooperação e o aumento da excelência científica;

d) pesquisa aplicada, que apresenta como principais características alto risco, pesquisa básica orientada e alto orçamento;

e) formação de grupos de consórcio associados com laboratórios de pesquisa e empresas de nível nacional.

Em todos os tipos de interação citados, a universidade deve possuir um caráter empreendedor para que a interação possa ocorrer (Ganzarain et al., 2019). A universidade precisa assumir uma postura empreendedora, buscando encontrar pesquisas realizadas 
dentro do contexto da academia que possam servir como potenciais tecnológicos e ser colocados em prática (Ełzkowitz, 2009). Tal postura empreendedora pode ser percebida quando a universidade se envolve com educação empreendedora, com transferência de tecnologia e com formação de novas empresas pelo processo de incubação. Essa cultura empreendedora poderá atuar como incentivadora para o corpo docente de uma universidade, que tradicionalmente possui foco em suas pesquisas, passando a criar um olhar voltado para um novo potencial, o mercadológico (Ełzkowitz \& Leydesdorff, 2000).

O papel das universidades empreendedoras não apenas gera/transfere conhecimento, mas também contribui/fornece liderança para a criação de pensamentos, ações e instituições empreendedoras (Guerrero et al., 2016). Os "empreendedores políticos" desempenham um papel poderoso no reforço cumulativo do papel dominante das universidades por meio de um processo de "captura institucional", que resulta em uma forma de "política de aprisionamento" (Brown, 2016).

As universidades empreendedoras atuam como impulsionadoras de atividades de inovação e empreendedorismo (Guerrero et al., 2016). Essas instituições desempenham, portanto, um papel relevante no crescimento econômico regional, contribuindo para o empreendedorismo acadêmico e o estabelecimento e o apoio de empresas derivadas de pesquisadores universitários com base em pesquisas acadêmicas (Hayter, 2016).

Ressalta-se, ainda, que os fatores informais (como atitudes e modelos) exercem uma influência maior na atividade empreendedora da universidade do que os fatores formais (como medidas de apoio, educação e treinamento). Existe, além disso, maior contribuição das universidades na competitividade regional, em particular quando se usam medidas sociais (capital humano de talento) em vez de medidas econômicas (Produto Interno Bruto per capita) (Guerrero et al., 2016). As contribuições das universidades dependem da existência e da inter-relação de intermediários de conhecimentos heterogêneos, pouco coordenados, guiados por um forte espírito coletivo para encorajar e apoiar o empreendedorismo acadêmico (Hayter, 2016).

A maioria das universidades comprometidas com a comercialização de pesquisas acadêmicas estabeleceu polos de transferência de tecnologia. No entanto, muitos pesquisadores ignoram esse aspecto e levam suas invenções diretamente ao mercado. Sabese, também, que a conscientização acerca da transferência de tecnologia é maior entre pesquisadores que possuem experiência como empreendedores, fecharam muitos contratos de pesquisa e consultoria com parceiros da indústria, realizaram pesquisas em medicina, engenharia ou ciências da vida ou ocuparam cargos de pós-doutorado (Huyghe et al., 2016). 


\subsection{SPIN-OFFS ACADÊMICAS}

Uma spin-off é uma empresa formada para comercializar uma tecnologia originada em um laboratório de uma universidade, podendo ser considerada uma forma de transferência de tecnologia, ou seja, de transferência de um core technology (Ferri et al., 2019). Todo processo de criação de uma spin-off requer o envolvimento de alguns agentes principais que, segundo Carayannis et al. (2018), são: gerador da tecnologia - o inventor, aquele que levará a tecnologia até sua transferência; empreendedor - o criador do novo negócio, responsável por comercializar a tecnologia; a organização de origem - local onde as pesquisas para a criação da tecnologia são realizadas e que dará assistência para o patenteamento, o licenciamento, etc.; e investidor - quem fornecerá recursos financeiros e administrativos à spin-off.

Uma das contribuições da universidade para o aumento das empresas de alta tecnologia são justamente as spin-offs. Essas empresas são geradas por acadêmicos ou suas instituições, com o objetivo de explorar e comercializar o P\&D interno (Etzkowitz et al., 1998). Geralmente envolvem o desenvolvimento de uma oportunidade de negócio baseada em tecnologia inovadora e potencialmente disruptiva ou em conhecimento tácito emergente da pesquisa acadêmica, de modo que os originadores dessa tecnologia não possuem habilidades e recursos para difundir esse novo produto ou processo (Huyghe et al., 2016).

O surgimento das spin-offs ocorre, conforme Borges e Filion (2013), a partir de um estudante que, durante o término de sua graduação ou até mesmo pós-graduação, juntamente com seus professores e/ou pesquisadores, adquire um conhecimento tecnológico e desenvolve um novo produto, que poderá ser utilizado pela universidade com o apoio de uma incubadora de negócios, explorando comercialmente essa tecnologia criada. Caso isso aconteça, os estudantes tornam-se empresários que, junto da empresa-mãe, neste caso a universidade, passarão a comercializar o produto ou a tecnologia criada, a partir da spin-off, empresa-filha (Boh et al., 2016).

Embora as universidades tenham admirado a participação de seus alunos de graduação e pós-graduação na geração dessas empresas a partir de suas pesquisas, esses alunos necessitam de apoio ao empreendedorismo inovador por meio de disciplinas que possam instruí-los gerencialmente, possibilitando uma visão mercadológica da invenção. De acordo com Araújo et al. (2005), as universidades que investem no empreendedorismo acadêmico por intermédio da criação de spin-offs recebem benefícios considerados importantes para o seu papel na sociedade. Esses benefícios são ilustrados na Figura 1. 


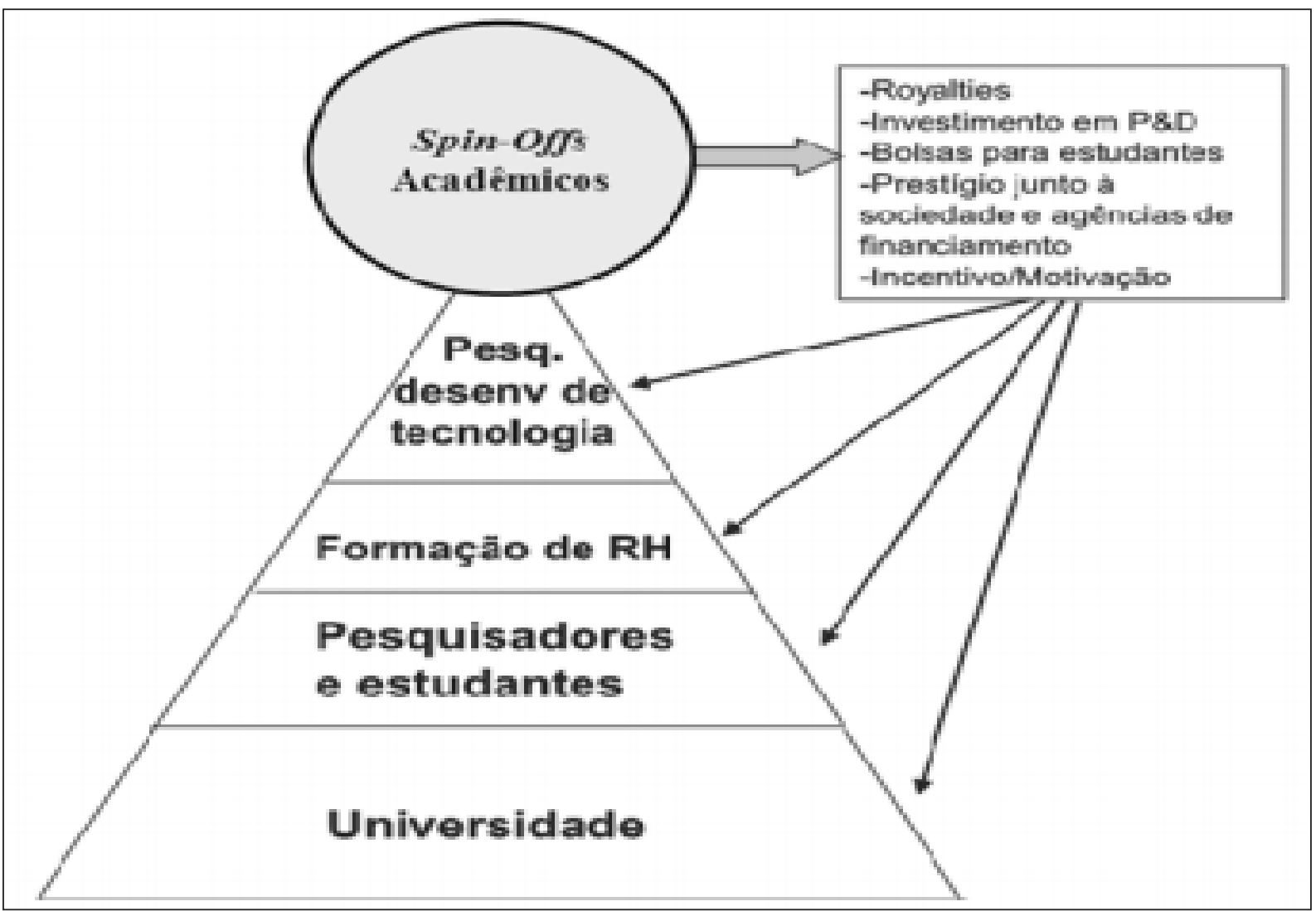

Figura 1. Benefício das spin-offs para as universidades. Adaptada de "'Spin-Off' acadêmico: criando riquezas a partir de conhecimento e pesquisa," de M. H. Araújo, R. M. Lago, L. C. Oliveira, P. R. Cabral, L. C. Cheng, C. Borges, e L. J. Filion, 2005, Química Nova, 28, p. S27.

Além dos benefícios apresentados na Figura l, há o benefício financeiro, pois a universidade receberá os royalties gerados a partir dos licenciamentos das tecnologias e terá facilidade em investimentos em P\&D mediante agências de fomento e até mesmo na geração de bolsas pagas por empresas para seus estudantes (Huyghe et al., 2016). No Brasil, a criação de spin-offs e a transferência de tecnologia por meio do licenciamento ainda são incipientes em comparação à realidade de outros países, sendo utilizados pelas universidades brasileiras os chamados serviços tecnológicos (Gonçalves, 2012).

A transição de empresas industriais para empresas do conhecimento ocorre desde o século XIX, porém as ideias e os objetivos envolvidos nessa transição vêm se alterando. A partir do momento em que o conhecimento faz parte da produção e comercialização de bens, produtos e serviços, as organizações buscam cultivar parcerias e convênios com outras áreas (Ełzkowitz, 2009).

De início, as empresas tendem a criar parcerias com outras pertencentes a ramos similares. Na sequência, procuram parcerias com empresas maiores, como startups, centros de pesquisa ou universidades. Atualmente, as grandes empresas transferiram unidades para os chamados parques tecnológicos ou parques científicos, instalados dentro das universidades e dos centros de pesquisa, para, assim, efetivarem convênios e estarem próximas ao conhecimento 
gerado pela pesquisa básica e aplicada, desenvolvida em grupos de pesquisa acadêmica, visando ao licenciamento de novos produtos com potencial mercadológico (Ełzkowitz, 2009).

Nesse cenário, a iniciativa privada deve ter como responsabilidade desenvolver produtos e serviços inovadores, promover a interação com a comunidade científica e liderar processos de mudança. Entretanto, são visíveis as limitações presentes nessa parte da hélice, como, por exemplo, pouca capacidade de investimento para o desenvolvimento de novas tecnologias e despreparo acadêmico e tecnológico para a condução de pesquisas (Abdala et al., 2009).

Organizações inovadoras têm reconhecido o valor da colaboração entre parceiros bem pareados. Universidade e laboratórios do governo podem constituir parceiros particularmente atraentes, já que muitas vezes têm capacidades únicas, experiência e portfólios de propriedade intelectual (Schoppe \& Chylla, 2016). A importância e a participação da universidade no processo de inovação são inquestionáveis, de modo que novos mecanismos de interação entre empresas universitárias e governo devem ser constantemente revisados e aprimorados para permitir o desenvolvimento econômico e social (Pereira et al., 2016).

Nesse sentido, as relações entre hélices podem ser vistas, considerando-se a perspectiva da proximidade, como pré-condições de conectividade ou interação, medidas por meio de expectativas e experiências. A tríplice hélice oferece, assim, uma solução potencial para duas limitações da abordagem de proximidade: sua natureza estática e seu foco estrito nas relações diádicas (Virkkala et al., 2017).

\subsection{INOVAÇÃO}

Schumpeter (1934) defendia que as economias capitalistas são sustentadas pelo impacto das inovações tecnológicas, em que as novas tecnologias substituem as antigas, ideia que contrapõe a teoria neoclássica. Nessa mesma época, propôs uma lista de inovações: de produtos, de métodos de produção, de abertura de novos mercados, de novas estruturas de mercado em uma indústria e de novas fontes de matéria-prima (Schumpeter, 1942).

Para uma melhor compreensão do caminho da inovação, houve o desenvolvimento da trilogia schumpeteriana, que compreende invenção, inovação e difusão. Essa trilogia destacada por Joseph Schumpeter (1934) é composta por autores que formam a corrente neoschumpeteriana e que configuram as seguintes abordagens teóricas: ótica da firma e ótica do padrão tecnológico, as quais definem o paradigma tecnoeconômico. Esses autores são Richard Nelson, Sidney Winter, Giovanni Dosi, Christopher Freeman, Carlota Perez e Luc Soete. 
O progresso econômico movido pelos avanços tecnológicos e pelo crescimento da inovação influencia diretamente a evolução das nações. Tendo isso em vista, em 1963 surgiu - Manual de Frascati, com o objetivo de criar um sistema padrão para a avaliação em $P \& D$, organizado pela Organização para Cooperação e Desenvolvimento Econômico (OCDE). Esse manual entende a inovação como a transformação de uma ideia em um produto vendável, novo ou melhorado, em um processo produtivo ou, ainda, em um novo método de serviço social.

Em 1992, em continuidade a esses estudos, surge a primeira versão do Manual de Oslo, com o intuito de guiar a compilação de dados sobre inovação tecnológica. A inovação passa a ser percebida como um processo dinâmico em que o conhecimento é acumulado por meio do aprendizado e da interação (Organisation for Economic Co-operation and Development [OECD], 2015), e pode ser classificada, segundo o Manual de Oslo (OECD, 2005), em quatro dimensões: inovação de produto, de processo, de marketing e organizacional.

Pode-se afirmar que inovação tecnológica ocorre quando há mudanças significativas em produtos, bens e serviços ou quando há a introdução de um novo produto no mercado nacional ou internacional. Assim, a inovação pode abarcar mudanças na qualidade e na produtividade, tornando o bem ou serviço mais próximo da real situação desejada pelo mercado (Zen et al., 2017). Dessa forma, enquanto a inovação tecnológica de produto pode ser conceituada como uma ideia transformada em um produto novo ou melhorado, que seja comercializável, a inovação tecnológica em processo pode ser entendida como um processo novo realizado na indústria ou até mesmo no comércio (OECD, 2015).

Cabe mencionar, ainda, que os ciclos de vida de um produto atualmente são curtos e que a renovação se faz necessária antes que o ciclo acabe. Isso requer pesquisa, conhecimento aplicado e assimilação rápida de conhecimento, o que evidencia o papel da inovação tecnológica para o ambiente competitivo e globalizado das organizações (Tidd et al., 2005).

Nesse contexto, as empresas de manufatura precisam suportar uma crescente concorrência global em diferentes dimensões estratégicas, como custos de produção, qualidade do produto e inovação de produtos. Para lidar com essa crescente concorrência, as organizações de países com altos salários costumam empregar uma estratégia de diferenciação para atender às necessidades individuais dos clientes (Brettel et al., 2016).

Embora as estratégias de inovação sejam cada vez mais interorganizacionais, as empresas podem achar difícil escolher o tipo apropriado de cooperação. A cooperação é frequentemente considerada como um empreendimento de maior risco, o que pode levar à conclusão de que essa estratégia não é a mais adequada para aumentar a inovação de uma empresa (Le Roy et al., 2016). 
Assim, a crescente necessidade de capacidade de absorção nas empresas enfatiza o papel fundamental da pesquisa universitária para colaboração, transferência de conhecimento e inovação de produtos (Ciliberti et al., 2016). Além disso, sabe-se que as empresas que estão abrindo seu processo de inovação e que utilizam fontes de informação diferentes têm maior capacidade de gerar inovações, ainda que a importância de fontes externas de informação varie dependendo do tipo de inovação (produto ou processo) considerado (Gómez et al., 2016).

\section{PROCEDIMENTOS METODOLÓGICOS}

Este estudo, com duas unidades de análise, caracteriza-se por ser de poucos objetos, mas amplo e detalhado, para que propicie um conhecimento aprofundado do assunto abordado. Conforme esclarece Yin (2013), é fundamental o estudo de mais de um caso, para que, assim, sejam possíveis comparações entre ambos, validando e tornando confiável a pesquisa.

Esta investigação adota uma abordagem qualitativa, que possibilita conhecer um fenômeno em profundidade (Yin, 2013). Assim, a coleta de dados para este estudo começou com uma definição do perfil das universidades a serem investigadas. Além da pesquisa bibliográfica e da análise documental, procedeu-se à entrevista estruturada, composta de dois roteiros: um com 19 questões aplicadas aos pesquisadores e outro com 18 questões aplicadas aos gestores e empresários. A técnica de análise de conteúdo e o tratamento dos dados foram efetuados por meio do software $N V i v o{ }^{\circledR}$, versão 10 (Bardin, 2010; Flick, 2016; Minayo, 2017). A seguir, na Tabela l, consta a lista dos participantes que foram entrevistados.

Tabela 1

Característica dos entrevistados

\begin{tabular}{llll}
\hline \multicolumn{1}{c}{ Cargo } & Área de Atuação & Instituição & $\begin{array}{c}\text { Foco que representa na } \\
\text { interação U-E }\end{array}$ \\
\hline $\begin{array}{l}\text { Gerente de comunicação do Núcleo de } \\
\text { Inovação Tecnológica (NIT) }\end{array}$ & Inovação & Unicamp & Universidade \\
$\begin{array}{l}\text { Gestora do NIT } \\
\text { Sócia-proprietária }\end{array}$ & $\begin{array}{l}\text { Inovação } \\
\text { Saúde }\end{array}$ & Unisinos & Universidade \\
Engenheira ambiental & $\begin{array}{l}\text { Engenharia am- } \\
\text { biental }\end{array}$ & Empresa & Empresa \\
Pesquisadora & Química & Unisinos & Universidade \\
Pesquisadora & Enfermagem & Unicamp & Universidade \\
\hline
\end{tabular}

A coleta dos dados primários foi feita mediante entrevistas semiestruturadas aplicadas in loco e em ambiente virtual, por meio de ferramentas de comunicação como Skype ${ }^{\circledR}$. Já os dados secundários foram coletados em relatórios técnicos, artigos, normativas 
das universidades e empresas e páginas eletrônicas das instituições. Após a aprovação do Comitê de Ética em Pesquisa das universidades participantes, foram realizados contatos com os coordenadores dos escritórios de transferência de tecnologia e da agência de inovação dos dois objetos de estudo para o agendamento das entrevistas com os professores, os gestores do escritório de transferência de tecnologia e os empresários envolvidos com a pesquisa.

Na sequência, foram iniciadas as entrevistas semiestruturadas, gravadas por meio de gravador portátil, direcionadas aos coordenadores de escritório. Os instrumentos para a coleta de dados foram validados por dois doutores pesquisadores dessa área e aprovados pelo Comitê de Ética em Pesquisa, tendo sido formulados a partir de informações de instrumentos publicados em dissertações da área estudada (Maçonetto, 2010; Soria, 2011). A aplicação das entrevistas resultou em 3 horas e 32 minutos de gravação, que geraram oito páginas de transcrições.

Na Figura 2 são apresentadas a categoria e suas duas subcategorias de análise.

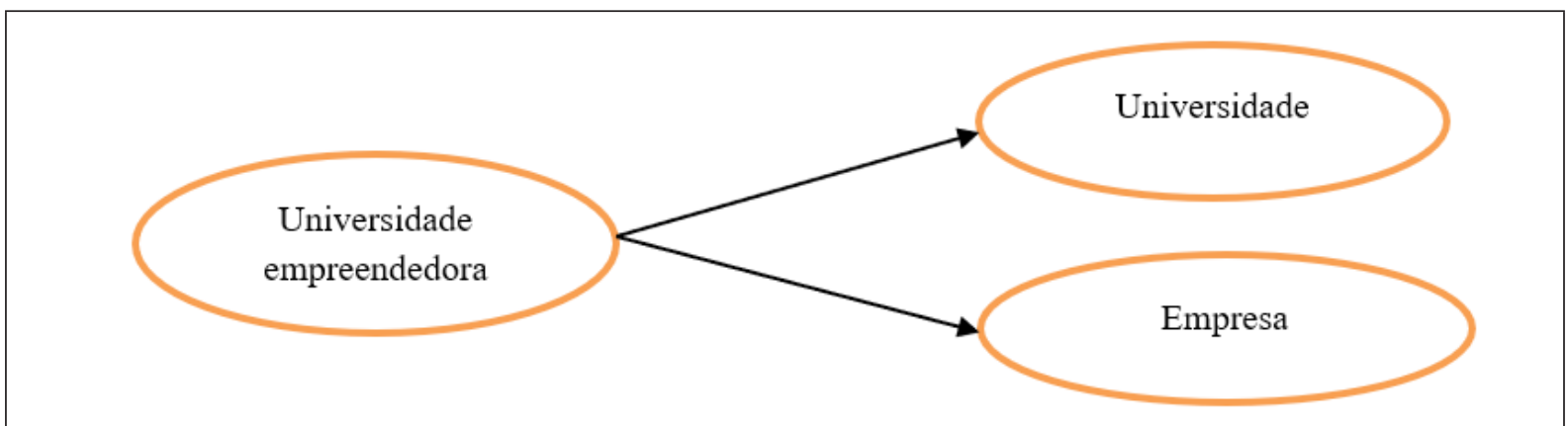

Figura 2. Categoria e subcategorias de análise

As categorias para análise de dados foram definidas a partir do conceito de universidade empreendedora de Etzkowitz (2009) e de difusão tecnológica de Rogers (1971), atendendo ao objetivo proposto e à questão central desta pesquisa, conforme demonstra a Figura 2.

\section{RESULTADOS DA PESQUISA}

\subsection{UNIVERSIDADE EMPREENDEDORA}

A partir dos dados coletados, apresentam-se os resultados da análise realizada com o auxílio do software $\mathrm{NVivo}^{\circledR}$. Na Tabela 2 é possível perceber a importância da universidade empreendedora para os entrevistados, pois todos a citaram em suas falas. Por intermédio da 
ferramenta do software chamada de consulta de pesquisa de texto, foi possível contabilizar que a expressão apareceu 110 vezes, apresentando uma frequência maior nas entrevistas dos participantes associados ao NIT, seguida das entrevistas dos empresários e, por último, nas entrevistas dos pesquisadores.

Tabela 2

Frequência universidade empreendedora

\begin{tabular}{lrr}
\hline Entrevistado & Identificação & Frequência \\
\hline Pesquisador Unicamp & El & 12 \\
Pesquisador Unisinos & E2 & 06 \\
NIT Unicamp & E3 & 40 \\
NIT Unisinos & E4 & 23 \\
Empresa parceira Unicamp & E5 & 12 \\
Empresa parceira Unisinos & E6 & 17 \\
\hline Total & & 110
\end{tabular}

Nota. elaborada a partir do software NVivo ${ }^{\oplus}$.

Os relatos dos entrevistados revelaram que ambas as instituições de ensino se consideram empreendedoras, como demonstram os excertos transcritos a seguir:

Sim, a Unicamp é uma universidade empreendedora, e, do lado da pesquisa, a gente entende que a universidade, ela tem que ter um impacto no regional, é um impacto que vai além do impacto do ensino, a inovação, ela tem como objetivo criar este impacto. Então a gente busca oportunidades de fazer com que o impacto da nossa pesquisa tenha um impacto regional, seja no número de empregos, na criação de novos negócios, e por consequência em número de empregos de altíssima qualidade, porque a gente está falando aí de negócios de base tecnológica principalmente (El, comunicação pessoal, 9 de dezembro de 2016).

Uma universidade empreendedora é uma universidade que se empenha em demonstrar principalmente para os seus pesquisadores o quanto é importante fazer pesquisa universidadeempresa. Hoje se estudam várias formas de apoio, o professor não precisa estar em Programa de Pós-Graduação (PPG) para fazer projeto de pesquisa, ele, prevendo o pagamento dele, ele pode estar há seis meses dentro da Unisinos e propor um projeto de pesquisa. É um caminhar longo, mas hoje eu considero que sim, a Unisinos é uma universidade empreendedora (E2, comunicação pessoal, 27 de dezembro de 2016).

Outro fator averiguado é que as empresas entrevistadas conseguem perceber essa diferença entre uma universidade tradicional, totalmente voltada para o ensino, e uma universidade empreendedora, conforme indicam os relatos a seguir: 
[...] a diferença é o nível e volume de pesquisas aplicadas, que reflete na disponibilização de tecnologias e infraestrutura para a sociedade, criando assim condições mais propícias ao desenvolvimento de empresas (E5, comunicação pessoal, 9 de dezembro de 2016).

Sim, é possível perceber a diferença da tradicional para a empreendedora, na medida em que desempenham juntos projetos de pesquisa, inovações, certificações (E6, comunicação pessoal, 27 de dezembro de 2016).

Porém, para os entrevistados, a comunidade não tem essa mesma facilidade de compreender a diferença. De acordo com o NIT da Unicamp, "embora a universidade tenha uma postura um pouco diferente das demais, desde sua criação, isso não é claro para a comunidade externa" (E3, comunicação pessoal, 9 de dezembro de 2016). De acordo com a pesquisadora da Unisinos, "as pessoas ficam completamente admiradas quando sabem que eu desenvolvi juntamente com duas empresas um produto que hoje está no mercado. Elas ainda têm aquela ideia que a universidade forma pessoas, ponto. Ainda não se tem essa cultura" (E2, comunicação pessoal, 27 de dezembro de 2016).

Uma universidade empreendedora deve buscar realizar pesquisas dentro do contexto da academia que possam servir como potenciais tecnológicos a serem colocados em prática. Esse conceito explicita claramente o entendimento que os entrevistados apresentaram sobre esse assunto (Etzkowitz, 2009).

\subsection{INTERAÇÃO UNIVERSIDADE-EMPRESA}

Para ambos os entrevistados dos NITs (E3 e E4), a interação com a empresa pode iniciar de maneiras diferentes. Segundo o NIT da Unicamp (E3), há um portfólio de empresas com as quais a Inova Unicamp trabalha com maior frequência e dá preferência para oferecer um produto para licenciamento. Algumas dessas empresas estão presentes na Figura 3. 


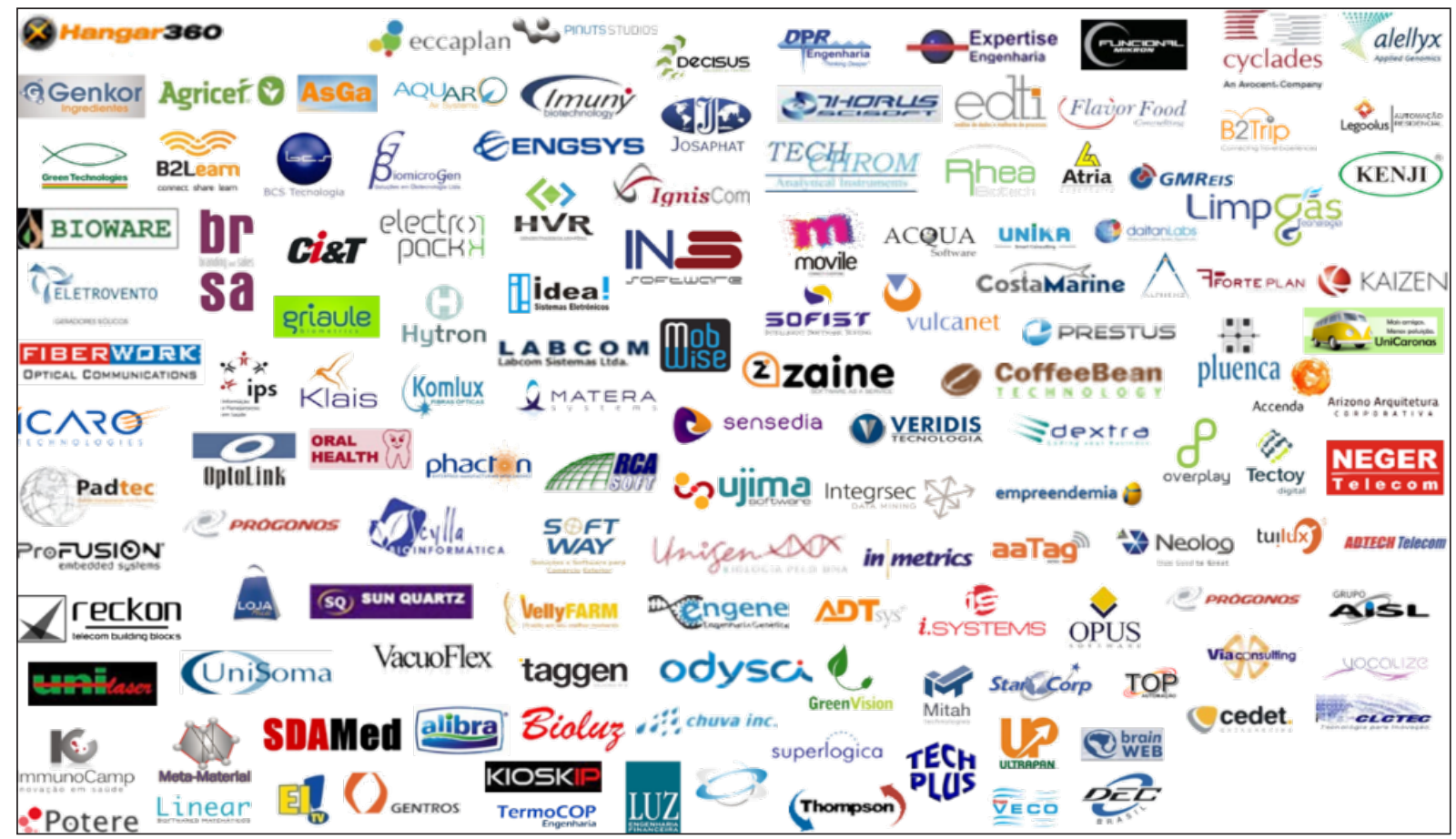

Figura 3. Portfólio de empresas da Unicamp. Adaptada de 'Inova Unicamp', de Universidade Estadual de Campinas, 2015, São Paulo. http://www.inova.unicamp.br/sobre

Para o NIT da Unisinos (E4), a interação pode iniciar por uma necessidade da empresa ou da própria universidade, conforme demonstra o excerto da entrevista transcrito a seguir:

\footnotetext{
Depende da situação, se tem um edital, que exige a presença de uma empresa, que tem contrapartida financeira, a gente elenca as empresas potenciais, mostra o edital, revela os benefícios, e enfim é uma relação de negociação. Agora, quando a empresa procura, a situação é diferente. Porque a gente tem que ver qual a expertise a gente tem na casa, direcionar para eles e colocar em contato, fazer um orçamento, um cronograma, e começar a trabalhar, então são situações diferentes (E4, comunicação pessoal, 27 de dezembro de 2016).
}

De acordo com a coordenadora do NIT da Unisinos (E4), muitos dos contatos que iniciam pela Universidade são feitos a partir de relações existentes entre o corpo técnico e as empresas, ou até mesmo a partir de contatos dos alunos. Essas situações vão ao encontro do entendimento de Lemos e Cario (2003) e Pereira et al. (2016), que afirmam que o processo de interação universidade-empresa começa no momento em que o setor produtivo necessita de uma nova tecnologia ou até mesmo quando o setor científico produz ou gera novos conhecimentos que possuem aplicações práticas, levando ao surgimento da interação entre esses setores para a promoção da inovação tecnológica. 
Os entrevistados também foram questionados acerca do preparo da universidade para essa interação. A seguir são apresentados trechos de algumas entrevistas que tratam desse quesito.

\begin{abstract}
Universidades: A primeira coisa que tem que haver é um ajuste de tempo. A gente não pode dar o resultado para a empresa ao final de quatro anos, eles não podem depender de um resultado de uma dissertação ou de uma tese. Dependendo da área, a gente já consegue dar a resposta em um tempo hábil para a empresa, mas estabelecendo elos de confiança e um cronograma muito bem traçado. Um projeto deve ter no máximo seis meses. Tudo bem, ele pode até ter dois anos, mas tem que ter reunião todo mês, esclarecendo como está, explicando, porque é isso que eles estão acostumados (E3, comunicação pessoal, 9 de dezembro de 2016).
\end{abstract}

Empresas: É preciso diminuir a burocracia e ter cuidado com a negociação, pois os valores exigidos nos contratos são altos e muitas vezes não contemplam o risco do investimento na tecnologia embrionária que a pequena empresa assume (E5, comunicação pessoal, 9 de dezembro de 2016).

Acredito que falte maior divulgação dos trabalhos patenteados na universidade ou os cases de sucesso, pois, se não sabem disso, as empresas não investem (E6, comunicação pessoal, 27 de dezembro de 2016).

Pesquisadores: Na verdade, quando iniciamos não pensávamos em patentear o produto, mas a universidade abraçou a causa, pois viu potencial na tecnologia. O serviço que o NIT oferece é de primeiro mundo; nós pesquisadores não teríamos tempo para pensar em contrato ou riscos. Com isso precisamos que a universidade mantenha o investimento em nosso NIT e acreditando em nós pesquisadores (El, comunicação pessoal, 9 de dezembro de 2016).

A partir da opinião das universidades, fica visível a preocupação em nivelar o tempo da universidade com o tempo da empresa (Chais et al., 2018), preocupação essa que pode ser identificada na entrevista de uma das empresas, quando se refere à burocracia. Outra manifestação realizada por uma das empresas entrevistadas foi quanto à divulgação das patentes que a universidade possui, mencionando que as universidades necessitam divulgar melhor os resultados para que as empresas possam investir nas pesquisas geradas pela universidade.

Quanto à opinião dos pesquisadores entrevistados (El e E2), eles destacaram a importância do NIT para suas pesquisas com empresas. Um deles se referiu aos serviços do NIT como serviços de primeiro mundo, enfatizando o pouco tempo que o pesquisador possui para se dedicar à burocracia que a interação desses atores representa, o que comprova a exigência da Lei de Inovação, a criação dos Núcleos de Inovação e Transferência de Tecnologia nas Instituições de Ciência e Tecnologia (El). 
O segundo pesquisador revelou que a interação com a empresa traz melhorias até mesmo para sua atuação em sala de aula. De acordo com ele, a dedicação que a pesquisa necessita faz com que o contato com o mercado de trabalho fique cada vez mais distante, de modo que essa interação coloca o pesquisador novamente em contato com o mundo empresarial, refletindo diretamente na prática docente (E2). Outro fator importante observado na entrevista de um dos associados ao NIT (E4) diz respeito à gestão universitária, que é responsável por decidir entre seguir o caminho de uma universidade empreendedora ou não. Caso decida seguir tal percurso, é necessário agir com o profissionalismo que a área exige.

$\mathrm{Na}$ Figura 4 apresenta-se um resumo dos aspectos mencionados durante as entrevistas realizadas quanto à universidade empreendedora, conforme análise realizada.

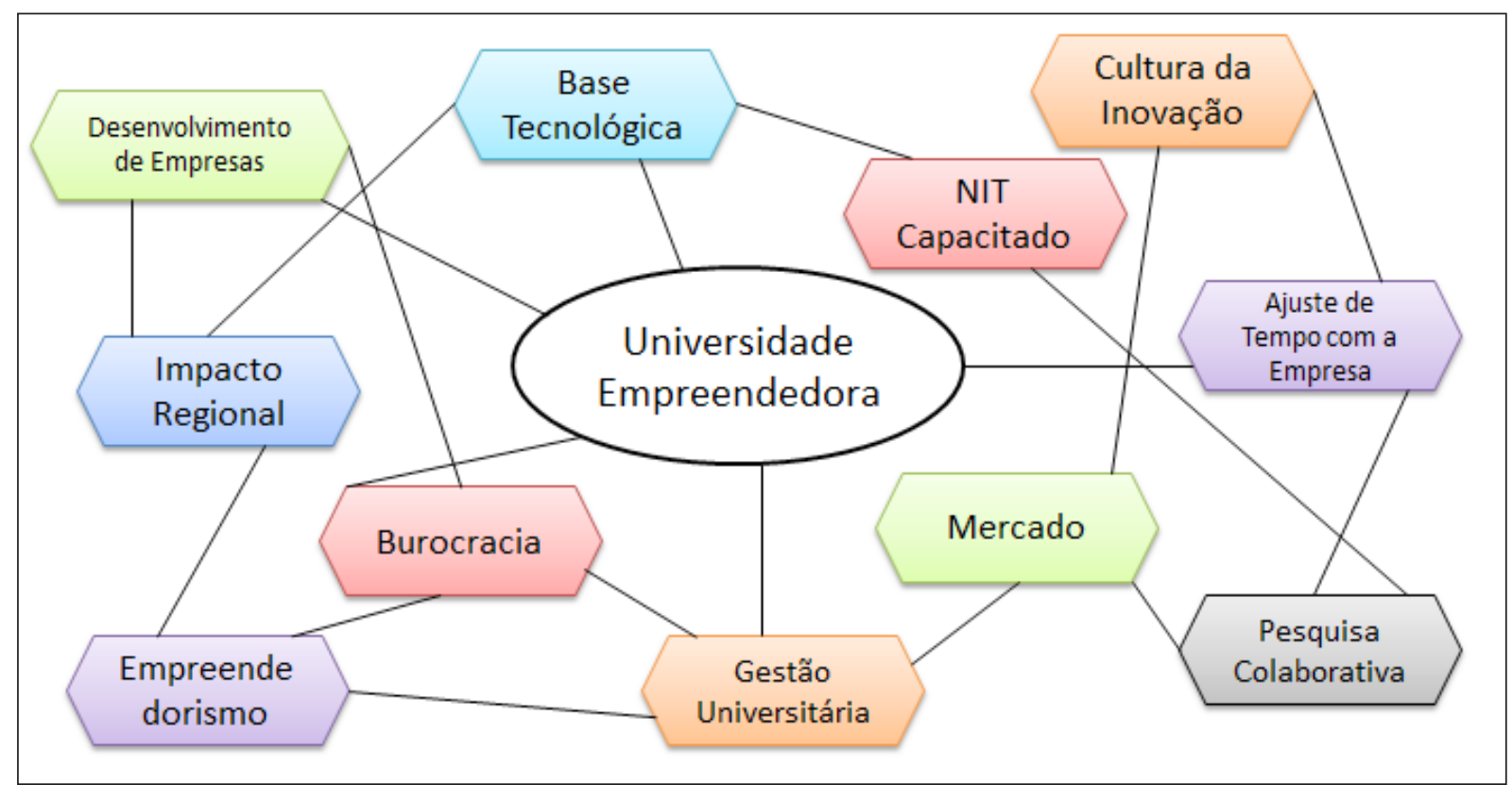

Figura 4. Principais aspectos relacionados à universidade empreendedora nos casos estudados. Elaborada a partir do software $\mathrm{NVivo}^{\circledR}$.

A partir da Figura 4, pode-se perceber que vários fatores mencionados nas entrevistas são fundamentais para caracterizar uma universidade como empreendedora. A gestão universitária deve apoiar e incentivar a cultura da inovação, a pesquisa colaborativa e - empreendedorismo, auxiliar o NIT na diminuição da burocracia, olhar para o mercado e desenvolver pesquisas de base tecnológica para a geração de empresas, ocasionando impacto regional pela transferência de tecnologias ao setor produtivo. Além disso, os aspectos "Gestão Universitária" e "Desenvolvimento de Empresas" estão diretamente relacionados com "Universidade Empreendedora", o que mostra a interação entre universidade e empresas.

A partir desta pesquisa, foi possível identificar, ainda, que existem pontos fracos e pontos fortes nos processos de interação universidade-empresa dos casos estudados. Como 
pontos fracos, citam-se a burocracia, a falta de cultura de inovação e empreendedorismo e a inexperiência tanto da universidade quanto da empresa em trabalhar em pesquisas colaborativas. Como pontos fortes dessa relação, observam-se a importância em aliar a teoria e a prática realizada mediante o auxílio das pesquisas colaborativas, a possibilidade de geração de novas tecnologias e o impacto regional que essas tecnologias podem gerar.

Vale ressaltar, também, que a interação entre universidades e empresas está em fase de consolidação. Percebe-se preocupação nos casos estudados com relação à prioridade de a gestão universitária não estar na universidade empreendedora, o que pode ser comprovado pela falta de políticas internas de inovação. Mesmo na Unicamp, que possui um volume maior de articulações e eventos que fomentam o empreendedorismo acadêmico, ainda não há uma política de criação de spin-offs, o que dificulta o trabalho das equipes dos NITs.

\section{CONSIDERAÇÕES FINAIS}

A universidade caracterizada como empreendedora consegue interagir com as empresas, pois procura aproximar as atividades desenvolvidas em seus laboratórios ou até mesmo em pesquisas das necessidades do mercado. Essa interação é gerada pela demanda do setor produtivo por uma nova tecnologia. Nesse sentido, define-se uma universidade empreendedora como aquela que apoia e incentiva a cultura da inovação e do empreendedorismo, auxilia o NIT a diminuir a burocracia de suas atividades, volta sua atenção para o mercado, desenvolve pesquisas com base tecnológica e auxilia na geração de novas empresas, ocasionando, assim, impacto tecnológico para a região.

Nas instituições investigadas neste estudo, percebeu-se uma preocupação quanto à prioridade de a gestão universitária não estar na universidade empreendedora, o que pôde ser comprovado com a falta de políticas internas de inovação. Mesmo na Unicamp, que possui articulações e eventos que fomentam o empreendedorismo acadêmico, ainda não há uma política de criação de spin-offs, o que dificulta o trabalho das equipes dos NITs.

As universidades pesquisadas também se preocupam com o ajuste do tempo das pesquisas às necessidades da empresa, que não pode esperar a conclusão de uma dissertação ou tese para difundir um produto no mercado. Assim, a empresa espera resultados de projetos que durem de seis meses até um ano, fato observado, por exemplo, em uma das entrevistas com um representante da Unicamp, que citou que a tecnologia foi licenciada para os próprios pesquisadores por meio de spin-off, em razão da duração da pesquisa, que existe há mais de 10 anos, e não para uma empresa do portfólio já existente.

A análise dessa interação permitiu concluir, ainda, que as universidades entrevistadas e seus pesquisadores percebem que a comunidade externa ainda não compreende a função da pesquisa, que inicia como um projeto de bancada na universidade e chega até o 
consumidor final como um produto, por meio da empresa. Para eles, a comunidade externa entende e vê a universidade apenas como formadora de profissionais.

Outro quesito importante a ser mencionado é o quanto agrega para o professor em sala de aula assumir o contato com o mercado de trabalho, o que por vezes se mostra algo difícil de ocorrer no caso de um professor pesquisador que possui vínculo de 40 horas semanais com a universidade, mas não possui carga horária destinada à pesquisa. A interação universidade-empresa faz com que esse pesquisador mantenha o elo com o mercado, tornando-o mais dinâmico e diferenciado em sala de aula.

De acordo com resultados da pesquisa, uma universidade empreendedora possui alguns aspectos que a caracterizam, sejam eles positivos ou negativos: ter uma gestão que compreenda e que queira se portar como empreendedora, estando disposta a realizar pesquisas colaborativas e de base tecnológica com foco no mercado; ter um NIT capacitado; fomentar o desenvolvimento de novas empresas e do empreendedorismo acadêmico; preocupar-se com o ajuste do tempo entre mercado e academia; e diminuir a burocracia e o retrabalho em suas atividades.

Como limitações desta pesquisa, é possível destacar que o estudo de dois casos não permite generalizar as informações e análises sobre a interação universidade-empresa. Dessa forma, sugere-se ampliar o estudo em outras instituições, bem como abordar as relações entre universidades públicas e privadas, para compreender como o processo de interação ocorre. Outra recomendação consiste em efetuar pesquisas relacionadas à mensuração e à criação de indicadores para os processos de transferência de tecnologia, a fim de tornar o fluxo mais claro e definido.

\section{REFERÊNCIAS}

Abdala, M. M., Calvosa, M. V. D., \& Batista, L. G. (2016). Hélice Tríplice no Brasil: Um ensaio teórico acerca dos benefícios da entrada da universidade nas parcerias Estatais. http:// www.fsma.edu.br/cadernos/Artigos/Cadernos_3_artigo_3.pdf

Araújo, M. H., Lago, R. M., Oliveira, L. C., Cabral, P. R., Cheng, L. C., Borges, C., \& Filion, L. J. (2005). "Spin-Off" acadêmico: Criando riquezas a partir de conhecimento e pesquisa. Química Nova, 28, S26-S35.

Audy, J. L. N., \& Morosini, M. (2006). Innovation and entrepreneurialism in the university. Edipucrs.

Bardin, L. (2010). Análise de Conteúdo. Edições 70. 
Boh, W. F., De-Haan, U., \& Strom, R. (2016). University technology transfer through entrepreneurship: Faculty and students in spinoffs. The Journal of Technology Transfer, 41(4), 661-669.

Borges, C., \& Jacques Filion, L. (2013). Spin-off process and the development of academic entrepreneur's social capital. Journal of technology management \& innovation, 8(1), 2134.

Lei n. 9.279, de 14 de maio de 1996.

Lei n. 10.973, de 2 de dezembro de 2004.

Lei n. 12.881, de 12 de novembro de 2003.

Brettel, M., Klein, M., \& Friederichsen, N. (2016). The relevance of manufacturing flexibility in the context of Industrie 4.0. Procedia Cirp, 4l, 105-110.

Brown, R. (2016). Mission impossible? Entrepreneurial universities and peripheral regional innovation systems. Industry and innovation, 23(2), 189-205.

Carayannis, E. G., Grigoroudis, E., Campbell, D. F., Meissner, D., \& Stamati, D. (2018). 'Mode 3 'universities and academic firms: Thinking beyond the box trans-disciplinarity and nonlinear innovation dynamics within competitive entrepreneurial ecosystems. International Journal of Technology Management, 77(1-3), 145-185.

Chais, C., Ganzer, P. P., \& Olea, P. M. (2018). Technology transfer between universities and companies. Innovation \& Management Review.

Ciliberti, S., Carraresi, L., \& Broering, S. (2016). Drivers of innovation in Italy: Food versus pharmaceutical industry. British Food Journal, 118(6), 1292-1316.

Comissão Econômica para a América Latina. (2018). https://www.cepal.org/pt-br/cepal-o

Espacenet. (2017). European Patent Office.

Ełzkowitz, H. E. (2009). Hélice tríplice: Universidade-indústria-governo inovação em ação. Edipucrs.

Etzkowitz, H. E. (2013). Anatomy of the entrepreneurial university. Social Science Information, 52(3), 486-511. 
Etzkowitz, H. E., \& Leydesdorff, L. (2000). The dynamics of innovation: From national systems and "mode 2" to a triple helix of university-industry-government relations. Research policy, 29(2), 109-123.

Etzkowitz, H. E., \& Zhou, C. (2017). The triple helix: University-industry-government innovation and entrepreneurship. Routledge.

Fava-de-Moraes, F. (2000). Universidade, inovação e impacto socioeconômico. São Paulo em perspectiva, 14(3), 8-11. http://www.scielo.br/scielo.php?script=sci_arttext\&pid $=$ S0102-88392000000300003\&lng $=$ pt\&nrm $=$ iso.

Ferri, S., Fiorentino, R., Parmentola, A., \& Sapio, A. (2019). Patenteando ou não? O dilema dos fundadores do spin-off acadêmico. Business Process Management Journal.

Flick, U. (2016). Challenges for a new critical qualitative inquiry: Introduction to the special issue. Qualitative Inquiry, 23(1), 3-7.

Formulário para Informações sobre a Política de Propriedade Intelectual das Instituições Científicas, Tecnológicas e de Inovação do Brasil. Ministério da Ciência, Tecnologia e Inovação. (2012). Política de propriedade intelectual das instituições científicas e tecnológicas do Brasil: Relatório Formict, 2012. Ministério da Ciência, Tecnologia e Inovação.

Ganzarain, J., Markuerkiaga, L., \& Igartua, J. I. (2019). Como o trabalho em projetos colaborativos universidade-empresa fomenta o processo de aprendizagem do doutorado industrial? Engineering Digital Transformation, 25(32).

Gómez, J., Salazar, I., \& Vargas, P. (2016). Sources of information as determinants of product and process innovation. PloS one, 11(4).

Gonçalves, E. J. V. (2012). Análise e desenvolvimento de modelos de negócio em spin-offs acadêmicos: Um estudo junto às empresas da INBATEC /UFLA (Dissertação de mestrado, Universidade Federal de Lavras, Lavras, Minas Gerais, Brasil).

Guerrero, M., Urbano, D., \& Fayolle, A. (2016). Entrepreneurial activity and regional competitiveness: Evidence from European entrepreneurial universities. The Journal of Technology Transfer, 41(1), 105-131.

Hayter, C. S. (2016). A trajectory of early-stage spinoff success: The role of knowledge intermediaries within an entrepreneurial university ecosystem. Small Business Economics, 47(3), 633-656. 
Huyghe, A., Knockaert, M., Piva, E., \& Wright, M. (2016). Are researchers deliberately bypassing the technology transfer office? An analysis of TTO awareness. Small Business Economics, 47(3), 589-607.

Instituto Brasileiro de Geografia e Estatística. (2016). Pesquisa de Inovação Tecnológica PINTEC 2014.

Instituto Nacional de Propriedade Industrial. (2016). Consulta a base de dados do INPI. http://formulario.inpi.gov.br/MarcaPatente/jsp/servimg/servimg.jsp?BasePesquisa=Patentes

Leih, S., \& Teece, D. (2016). Campus leadership and the entrepreneurial university: A dynamic capabilities perspective. Academy of Management Perspectives, 30(2), 182-210.

Lemos, D. C., \& Cario, S. A. F. (2017). University-industry interaction in Santa Catarina: Evolutionary phases, forms of interaction, benefits, and barriers. RAI Revista de Administração e Inovação, 14(1), 16-29.

Le Roy, F., Robert, M., \& Lasch, F. (2016). Choosing the best partner for product innovation: Talking to the enemy or to a friend? International Studies of Management \& Organization, 46(2-3), 136-158.

Lopes, V. F. (2012). A Inserção da Universidade Federal de Sergipe (UFS) no processo de inovação e desenvolvimento local: Intenção e prática (Tese de Doutorado, Universidade Federal de Pernambuco, Pernambuco, Brasil).

Minayo, M. C. D. S. (2017). Scientificity, generalization and dissemination of qualitative studies. Ciencia \& saúde coletiva, 22, 16-17.

Maçonetto, M. R. (2010). Políticas públicas em inovação: Um estudo comparativo entre as estratégias empregadas no Programa de Inovação Tecnológica (PIT) e no Programa Primeira Empresa Inovadora (PRIME) (Dissertação de Mestrado, Universidade de São Paulo, Ribeirão Preto, Brasil).

McClure, K. R. (2016). Building the innovative and entrepreneurial university: An institutional case study of administrative academic capitalism. The Journal of Higher Education, 87(4), 516-543.

Organisation for Economic Co-operation and Development. (2005). Oslo Manual. The measurement of scientific and technological activities.

Organisation for Economic Co-operation and Development. (2015). Frascati Manual. Guidelines for collecting and reporting data on research and experimental development. 
Pereira, G. M. C., Castro, F. N., Lanza, L. N. M., \& Lanza, D. C. F. (2016). Overview of opportunities for graduates of higher education in Brazil: The role of innovation in the creation of new job markets. Ensaio.

Rogers, E. M. (1971). Diffusion of Innovations (3a ed.). Collier Macmillan Publishers.

Schoppe, L. A., \& Chylla, R. W. (2016). Collaborating with universities and government labs. Research-Technology Management, 59(1), 67-71.

Schumpeter, J. A. (1934). The theory of economic development. Harvard University Press.

Schumpeter, J. A. (1942). Capitalism, Socialism and Democracy. Harper.

Soria, A. F. (2011). Gestão da transferência de tecnologia na interação universidade-empresa (Dissertação de Mestrado, Pontifícia Universidade Católica do Rio Grande do Sul, Porto Alegre, Brasil).

Stal, E., \& Fujino, A. (2016). The evolution of universities' relations with the business sector in Brazil: What national publications between 1980 and 2012 reveal. Revista de Administração, 51(1), 72-86.

Tidd, J., Bessant, J., \& Pavitt, K. (2005). Managing innovation: Integrating technological, market and organizational change. John Wiley \& Sons.

Universidade Estadual de Campinas. (2015). Inova Unicamp. http://www.inova.unicamp.br/ sobre.

Virkkala, S., Mäenpää, A., \& Mariussen, Å. (2017). A connectivity model as a potential tool for smart specialization strategies. European Planning Studies, 25(4), 661-679.

World Intellectual Property Organization. (2017). Disponível em: https://www.wipo.int/patentscope/en/. Acesso em 02 de jan de 2017.

Yin, R. K. (2013). Validity and generalization in future case study evaluations. Evaluation, 19(3), 321-332.

Zen, A. C., Machado, B. D., López, A. I. J., Borges, M. C., \& de Menezes, D. C. (2017). Rota da inovação: uma proposta de metodologia de gestão da inovação. RAC-Revista de Administração Contemporânea, 21(6), 875-892. 